\title{
STRUCTURAL STUDY OF A NEW ANTITUMOR ANTIBIOTIC, KAZUSAMYCIN
}

\author{
Kanki Komiyama, Kenji Okada, Hirofumi OKa, Shigeru Tomisaka, \\ Tetsuji Miyano, Shinji Funayama and Iwao Umezawa \\ The Kitasato Institute, \\ 5-9-1 Shirokane, Minato-ku, Tokyo, Japan
}

(Received for publication September 27, 1984)

\begin{abstract}
The structure of a new antitumor antibiotic, kazusamycin produced by Streptomyces sp. No. 81-484, was determined on the basis of its spectral and chemical properties. Kazusamycin has a structure characteristic of an unsaturated, branched-chain fatty acid with a terminal $\delta$-lactone ring.
\end{abstract}

In the course of a continuing search for novel antitumor antibiotics of microbial origin, a new antitumor antibiotic kazusamycin $\left(\mathrm{C}_{33} \mathrm{H}_{48} \mathrm{O}_{7}\right.$, MW 556), which shows antitumor activity against experimental murine tumors, was isolated from the culture broth of Streptomyces sp. No. 81-484 ${ }^{1}$. The taxonomy of the producing organism, fermentation, isolation and physico-chemical and biological properties of this antibiotic have been reported in a preceding paper ${ }^{1)}$. This paper deals with the structure elucidation of kazusamycin.

\section{Chemical Structure of Kazusamycin}

As described in the preceding paper, UV and IR spectra of kazusamycin were similar to those of leptomycins $\mathrm{A}$ and $\mathrm{B}$, and the molecular formula of kazusamycin $\left(\mathrm{C}_{33} \mathrm{H}_{48} \mathrm{O}_{7}\right.$, MW 556) was established ${ }^{1}$. The molecular formulas and the molecular weights of leptomycins $\mathrm{A}$ and $\mathrm{B}$ and kazusamycin are summarized in Table $1^{1 \sim 3}$.

Leptomycin B was also isolated from the same strain that produced kazusamycin. Identification of leptomycin B was accomplished through comparison of UV, IR, MS, ${ }^{1} \mathrm{H}$ NMR and $[\alpha]_{\mathrm{D}}$ with data in the literature ${ }^{2,3)}$. Rf values of leptomycin B and kazusamycin on silica gel TLC are summarized in Table 2 .

${ }^{1} \mathrm{H} \mathrm{NMR}^{1)}$ and ${ }^{13} \mathrm{C}$ NMR spectra of kazusamycin were similar to those of leptomycin B. In the ${ }^{13} \mathrm{C}$ NMR spectrum of kazusamycin (Fig. 2, Table 3), almost the same signals as leptomycins $\mathrm{A}$ and B were observed including three carbonyl signals ( $\delta 164.4,170.7$ and 215.1) and six sets of olefinic signals [ $\delta 116.8$ (d), 120.1 (d), 122.1 (d), 122.7 (d), 128.9 (d), 130.3 (d), 134.9 (d), 135.6 (s), 136.8 (d), 139.3 (s), 151.5 (d) and 161.0 (s)]. Because signals corresponding to the ethyl moiety [o 13.6 (q) and $26.6(\mathrm{t})$ ] have been also observed, kazusamycin was assumed to have the same skeleton as leptomycin B. The difference between leptomycin B and kazusamycin is that the latter compound has one more oxygen atom than the former.

Most of the ${ }^{1} \mathrm{H}$ NMR and ${ }^{13} \mathrm{C}$ NMR assignments have been performed by comparisons of ${ }^{1} \mathrm{H}$ and ${ }^{13} \mathrm{C}$ NMR spectra of kazusamycin and leptomycin $\mathrm{B}$ and the results are summarized in Table 3. Four methylene signals ( $\delta$ 26.6, 40.8, 45.6 and 62.6) were observed in the ${ }^{13} \mathrm{C}$ NMR spectrum of kazusamycin while there were three $(\delta 26.6,40.9$ and 45.7$)$ in the ${ }^{13} \mathrm{C}$ NMR spectrum of leptomycin B. However, only seven methyl signals $[\delta 12.2,12.4,13.3,13.6(2 \times \mathrm{C}), 18.7$ and 20.9$]$ were observed in the 
Table 1. Molecular formulas and molecular weights of kazusamycin and leptomycins A and B.

\begin{tabular}{lcc}
\hline & $\begin{array}{c}\text { Molecular } \\
\text { formula }\end{array}$ & MW \\
\hline Kazusamycin & $\mathrm{C}_{33} \mathrm{H}_{48} \mathrm{O}_{7}$ & 556 \\
Leptomycin B & $\mathrm{C}_{33} \mathrm{H}_{48} \mathrm{O}_{6}$ & 540 \\
Leptomycin A & $\mathrm{C}_{32} \mathrm{H}_{46} \mathrm{O}_{6}$ & 526 \\
\hline
\end{tabular}

Table 2. Chromatographic behavior of kazusamycin and leptomycin B on TLC (Kieselgel $60 \mathrm{~F}_{254}$ DC-Fertigplatten, Merck).

\begin{tabular}{ccc}
\hline Solvent system & $\begin{array}{c}\text { Kazusa- } \\
\text { mycin }\end{array}$ & $\begin{array}{c}\text { Lepto- } \\
\text { mycin B }\end{array}$ \\
\hline $\mathrm{CHCl}_{3}-\mathrm{MeOH}(10: 1)$ & 0.28 & 0.40 \\
EtOAc- $\mathrm{MeOH}(40: 1)$ & 0.33 & 060 \\
\hline
\end{tabular}

Fig. 1. Structures of kazusamycin and related compounds.

\begin{tabular}{llll} 
Kazusamycin \\
$\begin{array}{l}\text { Diacetylkazusamycin } \\
\text { Leptomycin } \mathrm{A} \\
\text { Leptomycin } \mathrm{B}\end{array}$ & $\begin{array}{l}\mathrm{CH}_{2} \mathrm{CH}_{3} \\
\mathrm{CH}_{2} \mathrm{CH}_{3}\end{array}$ & $\begin{array}{l}\mathrm{CH}_{2} \mathrm{OH} \\
\mathrm{CH}_{3} \mathrm{OAc}\end{array}$ \\
$\mathrm{CH}_{2} \mathrm{CH}_{3}$ & $\begin{array}{l}\mathrm{CH}_{3} \\
\mathrm{CH}_{3}\end{array}$ & $\mathrm{Ac}$ \\
\hline
\end{tabular}

${ }^{13} \mathrm{C}$ NMR spectrum of kazusamycin while there were eight $[\delta 12.3,13.0(2 \times \mathrm{C}), 13.5,13.6,16.0,18.5$ and 20.9] in the case of leptomycin B. The fact that kazusamycin has seven methyl moieties $[\delta 0.79$ (d), 0.98 (d), 1.06 (t), 1.07 (d), 1.19 (d), 1.87 (s) and 2.13 (d)] was also proved by ${ }^{1} \mathrm{H}$ NMR analysis (Table 3). When kazusamycin was acetylated with acetic anhydride - pyridine, kazusamycin diacetate $\left(\mathrm{C}_{37} \mathrm{H}_{52} \mathrm{O}_{9}, \mathrm{M}^{+} 640\right)$ was obtained.

From these accumulated results, it was estimated that kazusamycin has the same skeleton as leptomycin B but one of the methyl moieties of leptomycin B [C-30 ( $\left.\delta_{\mathrm{H}} 1.07(\mathrm{~d}) ; \delta_{\mathrm{C}} 13.0(\mathrm{q})\right)$ or C-31 $\left.\left(\delta_{\mathrm{H}} 1.08(\mathrm{~d}) ; \delta_{\mathrm{C}} 20.9(\mathrm{q})\right)\right]$ was converted into a carbinol in kazusamycin, i.e., kazusamycin has two alcohol moieties which could be acetylated with acetic anhydride - pyridine instead of one for leptomycin B. The existence of the fourth methylene signal at $\delta 62.6$ in the ${ }^{13} \mathrm{C}$ NMR spectrum of kazusamycin also verified the existence of the carbinol moiety in this antibiotic.

In accordance with these changes, one of the methine signals of kazusamycin appeared at a field about $7 \sim 8$ ppm lower [ $\delta 53.8$ (C-16 or C-18)] than that of leptomycin B $[\delta 45.7(\mathrm{C}-16)$ or $47.0(\mathrm{C}-18)]$ and a $3 \sim 5$ ppm chemical shift changes for two olefin carbons (C-14 and C-15) have also been observed. Therefore, the position of the carbinol moiety of kazusamycin was estimated to be on the methine carbon next to the olefinic group, i.e. C-30 rather than C-31. The existence of the C-31 methyl moiety $\left[\delta_{\mathrm{C}} 20.9(\mathrm{q})\right]$ in kazusamycin also supported the above assumption.

In the ${ }^{1} \mathrm{H}$ NMR spectrum of kazusamycin, the methylene signals of the carbinol group were observed at $\delta 3.60(1 \mathrm{H}, \mathrm{m})$ and $3.88(1 \mathrm{H}, \mathrm{m})$ and by irradiation at $\delta 3.60$, signals at $\delta 3.88(\mathrm{H}-16$ and $\mathrm{H}-30)$ were simplified. On the other hand, when $\delta 3.88$ was irradiated, one of the methylene signals $[\delta 3.60$ $(1 \mathrm{H}, \mathrm{m})]$ and an olefinic signal $[\delta 5.05(1 \mathrm{H}, \mathrm{d})]$ were simplified. In addition, when the olefinic signal at $\delta 5.05$ was irradiated a methine signal at $\delta 3.88(1 \mathrm{H}, \mathrm{m})$ was simplified. Because $\delta 5.05(1 \mathrm{H}$, d) was assigned to $\mathrm{H}-15$, it was again confirmed that the position of the carbinol moiety is C-16 and that of the additional carbinol methylene is C-30.

From these accumulated data, the structures of kazusamycin and diacetylkazusamycin were 
Table 3. ${ }^{1} \mathrm{H}$ and ${ }^{13} \mathrm{C}$ NMR spectra of kazusamycin and leptomycin $\mathrm{B}\left(\mathrm{CDCl}_{3}\right)$.

\begin{tabular}{|c|c|c|c|c|}
\hline \multirow{2}{*}{ No. } & \multicolumn{2}{|c|}{$\delta_{\mathrm{H}}$} & \multicolumn{2}{|c|}{$\delta_{\mathrm{C}}$} \\
\hline & Kazusamycin & Leptomycin B & Kazusamycin & Leptomycin $\mathrm{B}^{\mathrm{b}}$ \\
\hline 1 & - & - & $164.4 \mathrm{~s}$ & $164.4 \mathrm{~s}^{\mathrm{c}}$ \\
\hline 2 & $6.011 \mathrm{H}, \mathrm{d}$ & $5.941 \mathrm{H}, \mathrm{d}^{* a}$ & $120.1 \mathrm{~d}$ & $120.0 \mathrm{~d}$ \\
\hline 3 & $6.971 \mathrm{H}, \mathrm{dd}$ & $6.901 \mathrm{H}, \mathrm{d}$ & $151.5 \mathrm{~d}$ & $151.6 \mathrm{~d}$ \\
\hline 4 & $2.541 \mathrm{H}, \mathrm{m}$ & $2.471 \mathrm{H}, \mathrm{m}$ & $33.6 \mathrm{~d}$ & $33.6 \mathrm{~d}$ \\
\hline 5 & $4.991 \mathrm{H}, \mathrm{dd}$ & $4.941 \mathrm{H}, \mathrm{dd}$ & $81.5 \mathrm{~d}$ & $81.5 \mathrm{~d}$ \\
\hline 6 & $5.711 \mathrm{H}, \mathrm{dd}$ & $5.661 \mathrm{H}, \mathrm{dd}$ & $122.1 \mathrm{~d}$ & $122.8 \mathrm{~d}$ \\
\hline 7 & $6.641 \mathrm{H}, \mathrm{d}$ & $6.591 \mathrm{H}, \mathrm{d}$ & $130.3 \mathrm{~d}$ & $130.2 \mathrm{~d}$ \\
\hline 8 & - & - & $135.6 \mathrm{~s}$ & $* 135.6 \mathrm{~s}$ \\
\hline 9 & $5.231 \mathrm{H}, \mathrm{d}$ & $5.161 \mathrm{H}, \mathrm{d}$ & $136.8 \mathrm{~d}$ & $136.9 \mathrm{~d}$ \\
\hline 10 & $2.681 \mathrm{H}, \mathrm{m}$ & $2.611 \mathrm{H}, \mathrm{m}$ & $32.2 \mathrm{~d}$ & $32.2 \mathrm{~d}$ \\
\hline 11 & $2.092 \mathrm{H}, \mathrm{dd}$ & $2.022 \mathrm{H}, \mathrm{t}$ & $40.8 \mathrm{t}$ & $40.9 \mathrm{t}$ \\
\hline 12 & $5.641 \mathrm{H}, \mathrm{dd}$ & $5.531 \mathrm{H}, \mathrm{m}$ & $128.9 \mathrm{~d}$ & $* * 128.2 \mathrm{~d}$ \\
\hline 13 & $6.001 \mathrm{H}, \mathrm{d}$ & $5.931 \mathrm{H}, \mathrm{d}^{*}$ & $134.9 \mathrm{~d}$ & $135.3 \mathrm{~d}$ \\
\hline 14 & - & - & $139.3 \mathrm{~s}$ & $* 136.5 \mathrm{~s}$ \\
\hline 15 & $5.051 \mathrm{H}, \mathrm{d}$ & $5.011 \mathrm{H}, \mathrm{d}$ & $122.7 \mathrm{~d}$ & $* * 128.0 \mathrm{~d}$ \\
\hline 16 & $3.881 \mathrm{H}, \mathrm{m}$ & $3.591 \mathrm{H}, \mathrm{m}$ & $53.8 \mathrm{~d}$ & $45.7 \mathrm{~d}$ \\
\hline 17 & - & - & $215.1 \mathrm{~s}$ & $214.9 \mathrm{~s}$ \\
\hline 18 & $2.801 \mathrm{H}, \mathrm{m}$ & $2.761 \mathrm{H}, \mathrm{m}$ & $47.8 \mathrm{~d}$ & $47.0 \mathrm{~d}$ \\
\hline 19 & $3.621 \mathrm{H}, \mathrm{t}$ & $3.511 \mathrm{H}, \mathrm{t}$ & $74.1 \mathrm{~d}$ & $74.2 \mathrm{~d}$ \\
\hline 20 & $1.751 \mathrm{H}, \mathrm{m}$ & $1.691 \mathrm{H}, \mathrm{m}$ & $33.6 \mathrm{~d}$ & $33.6 \mathrm{~d}$ \\
\hline \multirow[t]{2}{*}{21} & $1.931 \mathrm{H}, \mathrm{dd}$ & $1.841 \mathrm{H}, \mathrm{dd}$ & $45.6 \mathrm{t}$ & $45.7 \mathrm{t}$ \\
\hline & $2.191 \mathrm{H}, \mathrm{d}$ & $2.141 \mathrm{H}$, dd & & \\
\hline 22 & - & - & $161.0 \mathrm{~s}$ & $160.9 \mathrm{~s}$ \\
\hline 23 & $5.691 \mathrm{H}, \mathrm{s}$ & $5.611 \mathrm{H}, \mathrm{s}$ & $116.8 \mathrm{~d}$ & $117.1 \mathrm{~d}$ \\
\hline 24 & - & - & $170.7 \mathrm{~s}$ & $171.3 \mathrm{~s}$ \\
\hline 25 & $1.073 \mathrm{H}, \mathrm{d}$ & $1.003 \mathrm{H}, \mathrm{d}$ & $* 12.2 \mathrm{q}$ & $* 12.3 \mathrm{q}$ \\
\hline 26 & $2.202 \mathrm{H}, \mathrm{q}$ & $2.132 \mathrm{H}, \mathrm{q}$ & $26.6 \mathrm{t}$ & $26.6 \mathrm{t}$ \\
\hline 27 & $1.063 \mathrm{H}, \mathrm{t}$ & $1.003 \mathrm{H}, \mathrm{t}$ & $* 13.6 \mathrm{q}$ & $* 13.5 \mathrm{q}$ \\
\hline 28 & $0.983 \mathrm{H}, \mathrm{d}$ & $0.903 \mathrm{H}, \mathrm{d}$ & $* 12.4 \mathrm{q}$ & $* 13.0 \mathrm{q}$ \\
\hline 29 & $1.873 \mathrm{H}, \mathrm{s}$ & $1.763 \mathrm{H}, \mathrm{s}$ & $18.7 \mathrm{q}$ & $18.5 \mathrm{q}$ \\
\hline \multirow[t]{2}{*}{30} & $3.881 \mathrm{H}, \mathrm{m}$ & $1.073 \mathrm{H}, \mathrm{d}^{* *}$ & $62.6 \mathrm{t}$ & $* 13.0 \mathrm{q}$ \\
\hline & $3.601 \mathrm{H}, \mathrm{m}$ & & & \\
\hline 31 & $1.193 \mathrm{H}, \mathrm{d}$ & $1.083 \mathrm{H}, \mathrm{d}^{* *}$ & $20.9 \mathrm{q}$ & $20.9 \mathrm{q}$ \\
\hline 32 & $0.793 \mathrm{H}, \mathrm{d}$ & $0.723 \mathrm{H}, \mathrm{d}$ & $* 13.3 \mathrm{q}$ & $* 13.6 \mathrm{q}$ \\
\hline 33 & $2.133 \mathrm{H}, \mathrm{s}$ & $2.063 \mathrm{H}, \mathrm{s}$ & $* 13.6 \mathrm{q}$ & $16.0 \mathrm{q}$ \\
\hline
\end{tabular}

a $*, * *$ : Assignments may be interchanged.

b Reference 2 .

c Multiplicity in off-resonance spectrum.

Fig. 2. ${ }^{13} \mathrm{C}$ NMR spectrum $(50.1 \mathrm{MHz})$ of kazusamycin $\left(\mathrm{CDCl}_{3}\right)$.

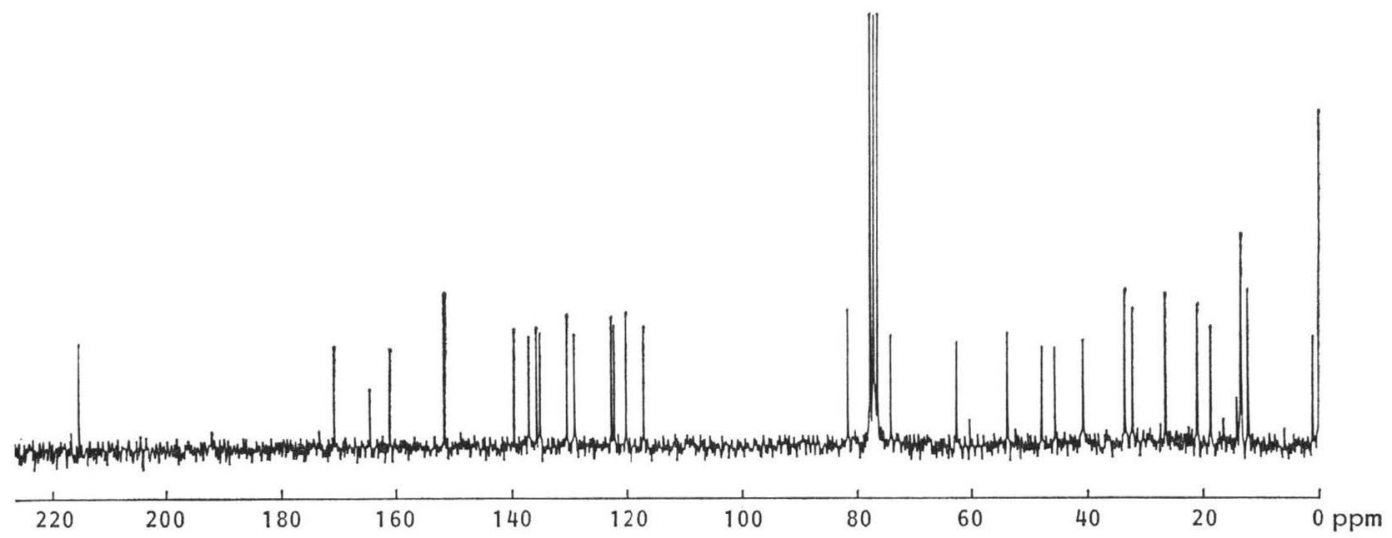


established as shown in Fig. 1.

Because both kazusamycin and leptomycin B have similar coupling constants of $J_{\mathrm{H} 2-\mathrm{H} 3}, J_{\mathrm{H} 6-\mathrm{H} 7}$ and $J_{\mathrm{H} 12-\mathrm{H} 13}$ and both of these compounds exhibited upfield chemical shifts of the methyl carbons at C-29 and C-33, the configurations at C-2, C-6, C-12, C-14 and C-22 of these compounds were shown to be the same, i.e., $Z, E, E, E$ and $E$, respectively ${ }^{3)}$.

We are presently investigating the structure-activity relationships of kazusamycin, leptomycin B and their derivatives and will report the results later.

\section{Experimental}

IR spectra were recorded with an A-102 (Jasco) spectrophotometer with polystyrene calibration at $1601 \mathrm{~cm}^{-1}$. UV spectra were measured with a Shimadzu UV 200S double beam spectrophotometer. ${ }^{1} \mathrm{H}$ and ${ }^{13} \mathrm{C}$ NMR spectra were obtained in $\mathrm{CDCl}_{3}$ with Jeol GX-400 and Jeol FX-200 spectrometers. Tetramethylsilane (TMS) was used as an internal standard and chemical shifts are recorded in $\delta$ ppm units. Mass spectra were taken on D-100 and DX-300 (Jasco) spectrometers. Optical rotations were measured with a DIP-181 (Jasco) polarimeter using methanol as solvent. TRI Rotar-V (Jasco) and Uvidec-100 (Jasco) instruments were used for HPLC with a Fine SIL C ${ }_{18}-10$ (Jasco), $10 \phi \times 250 \mathrm{~mm}$ column eluted with $\mathrm{MeOH}-\mathrm{H}_{2} \mathrm{O}(7: 3)$. Kieselgel $60 \mathrm{~F}_{254}$ DC-Fertigplatten plates (Merck) were used for TLC analyses.

\section{Isolation of Kazusamycin and Leptomycin B}

During the purification of kazusamycin from the fermentation culture of Streptomyces sp. No. 81-484, a minor active fraction which included leptomycin B was found after silica gel column chromatography eluted with hexane - acetone (gradient). These two components were purified by preparative HPLC to give kazusamycin and leptomycin B. Identification of leptomycin B was performed by comparison of UV, IR, MS and ${ }^{1} \mathrm{H}$ NMR data ${ }^{3)}$.

\section{Diacetylkazusamycin}

Kazusamycin $(10 \mathrm{mg})$ was dissolved in $1 \mathrm{ml}$ of pyridine. Acetic anhydride $(1 \mathrm{ml})$ was added to this solution and the solution was stirred for 24 hours at room temp. The reaction mixture was poured into cold water $(25 \mathrm{ml})$ and extracted with $\mathrm{CHCl}_{3}(2 \times 25 \mathrm{ml})$. Combined $\mathrm{CHCl}_{3}$ layers were washed with $\mathrm{H}_{2} \mathrm{O}(25 \mathrm{ml}), 1 \% \mathrm{HCl}$ aq solution $(25 \mathrm{ml})$ and $\mathrm{H}_{2} \mathrm{O}(25 \mathrm{ml})$ successively and dried over $\mathrm{Na}_{2} \mathrm{SO}_{4}$. Concentration of the $\mathrm{CHCl}_{3}$ layer in vacuo gave a pale yellow oil $(11.3 \mathrm{mg})$. By preparative HPLC of this fraction, diacetylkazusamycin $(5.0 \mathrm{mg})$ was obtained as a pale yellow oil.

\section{Acknowledgment}

This work was supported by a Grant-in-Aid from the Ministry of Health and Welfare, Japan, and WarnerLambert Fund. The authors would like to thank Dr. T. ENDo and Mr. T. Morota of Tsumura Juntendo Inc., Tokyo for part of NMR spectral data.

\section{References}

1) Umezawa, I.; K. Komiyama, H. OKa, K. Okada, S. Tomisaka, T. Miyano \& S. Takano: A new antitumor antibiotic, kazusamycin. J. Antibiotics 37: 706 711, 1984

2) Намамото, T.; S. Gunj, H. Tsuji \& T. Beppu: Leptomycins A and B, new antifungal antibiotics. I. Taxonomy of the producing strain and their fermentation, purification and characterization. J. Antibiotics 36: 639 645, 1983

3) Hamamoto, T.; H. Seto \& T. Beppu: Leptomycins A and B, new antifungal antibiotics. II. Structure elucidation. J. Antibiotics 36: 646 650, 1983 